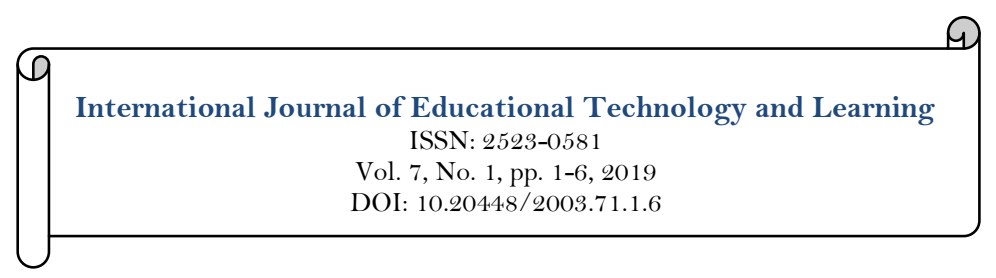

\title{
The Role of Virtual Reality in Enhancing Students' Learning
}

\author{
Sultan Hammad Alshammari
}

Department of Educational Technology, College of Education, University of Ha'il, Saudi Arabia. Email:Sh.alshammari@uoh.edu.sa Tel: +966555598256

\section{Abstract}

The globalization, innovation, and rapid spread of advanced technologies in different fields, including education, are a recent trend. Virtual reality (VR) is one emerging technology that has been used in recent years in medical training, military training, and other fields. It also presents several opportunities in the educational sector to support teaching and learning processes and thus deserves greater attention from educators and policy makers. The present paper reviews the huge role of Virtual Reality in supporting and enhancing students' learning in four main areas: collaborative/cooperative learning, creative learning, problem-based learning, and role playing. Different types and categories of $V R$ are also explored. Finally, some of the limitations associated with the implementation of VR, including its high cost, and possible solutions are discussed. Overall, $V R$ presents several unique opportunities for enhancing teaching and students' learning.
Keywords:

Virtual reality

$V R$

Technology

Educational technology

Education

Simulation.

Licensed:

This work is licensed under a

Creative Commons Attribution 4.0

License.

Publisher:

Scientific Publishing Institute

Accepted: 6 November 2019

Published: 27 November 2019

Funding: This study received no specific financial support.

Competing Interests: The author declares that there are no conflicts of interests regarding the publication of this paper.

\section{Introduction}

Currently, several emerging technologies have been implemented in the education sector, especially for supporting teaching and learning processes. The current generation of learners is highly capable of using computers and expects academic organizations and institutes to make use of advanced technologies to support the learning process. However, academic organizations and institutes may face challenges in implementing emerging technologies. Appropriate strategies must be employed to meet the demands of educational innovation. The development of immersive and interactive technology could play an important supporting role in several different styles of learning and teaching. In particular, virtual reality is one technology that is considered attractive by the student community. In fact, virtual reality is already widely used in different areas of education and training (Abulrub, Attridge, \& Williams, 2011) military training (Zyda, 2005) medical training and entertainment (Stapleton, Hughes, Moshell, Micikevicius, \& Altman, 2002).

Given the continuous demand for innovation in higher education and the enormous recent developments in computer hardware, software, and $3 \mathrm{D}$ visualization technology, the virtual reality environment can be utilized to support the various styles of teaching and learning. Notably, virtual reality technology has several application in technological fields and has the advantages of being cost-effective, safe, and fully controllable (Abulrub et al., 2011). As virtual reality encourages interactivity in a realistic environment, it can significantly enhance learning experiences. In the present paper, first, virtual reality is defined from different perspectives, and different categories and applications of virtual reality are presented. Then, the main aim was to illustrate the potential role of virtual reality in enhancing teaching and learning processes in four main ways, through 
encouraging collaborative/cooperative learning, creative learning, problem-based learning, and role playing. Finally, some of the challenges associated with virtual reality implementation in education are discussed.

\subsection{Definition of Virtual Reality}

The term "virtual reality" was originally coined by Conn, Lanier, Minsky, Fisher, and Druin (1989). Other similar terms were previously described, such as "artificial reality" (Krueger, 1970) "cyberspace" (Gibson, 1984) and, more recently, "virtual worlds" or "virtual environments". Today, virtual reality has many different applications, although it has been associated with a wide array of complex technologies. The term "virtual reality" originally referred to "immersive virtual reality", where users become fully immersed in an artificial, three-dimensional (3D) world generated by computers.

Therefore, virtual reality (VR) can be defined as the use of a computer-generated 3D environment called a virtual environment ( $\mathrm{VE}$ ) that allows users to navigate and possibility interact with one another in a simulated real-time environment that involves the five senses (Gutierrez, Vexo, \& Thalmann, 2008; Vince, 2004). "Navigate" refers to users' ability to explore and move around in a VE, while "interact" means the ability to move objects and select within a VE. Ultimately, VR can be described as a new communication technology that involves the human senses in unique ways and enables users to intuitively interact with data (McLellan, 1996). It requires a highly interactive computer-based multimedia environment where users become participants in a seemingly real virtual world (Pantelidis, 1993). A VR experience can provide users with a presence in a psychological sense and immersion in a physical sense (Gutierrez et al., 2008). "Immersion" refers to the extent that users are isolated from the real world. In a full immersive system, users are fully encompassed by a VE and do not interact with the real world, whilst in a semi-immersive or even nonimmersive system, users have some interaction with the real world (Gutierrez et al., 2008). The level of immersion provided by VR technology is one factor that might affect users' "presence" or "feeling" (Baños et al., 2004). The word "presence" in VR has different definitions; however, the most common definition is "the sense of being in a VE rather than the place in which the participant's body is actually located" (Sanchez-Vives \& Slater, 2005). Furthermore, presence is a sign that users in a VE can behave similar to how they would behave in a similar situation in their real life (Gutierrez et al., 2008). The feeling of "presence" is subjective and related to users' psychology. However, it is undoubtedly influenced by the ability of the VR to provide highquality data to users' senses (Gutierrez et al., 2008; Guttentag, 2010). In summary, VR is a type of technology that allow users to navigate and interact with a simulation in real time that influences users' five senses, thereby providing them with the experience of psychological and physical presence in the VR.

\subsection{Categories of Virtual Reality}

Researchers have differentiated VRs into several categories. However, there are two main types of VR technologies: desktop-based VR and immersive VR hardware. Desktop-based VR depends on traditional output/input devices, such as a mouse, monitor, keyboard, speakers, and microphone, while immersive VR is recreated with body suits or data gloves, simulators, shared workbenches, etc. Due to the higher cost, immersive VRs are not convenient for everyday use.

Desktop-based VR can be structured based on system-inherent proprieties and advanced technological properties (Schwienhorst, 1998) which enable them to be fairly useful for innovative learning purposes. Also, it provides an easy-to-use interface for multiple users and flexibility in addition to enabling the integration of resources in a common environment and ideation learning tools.

On the other hand, immersive VR is presented on multiple room-sized screens or on a stereoscopic unit on a mounted head display. Other equipment such as data gloves enable users to interact with the VE by normal movements of their body. Data gloves and sensors on a head unit can track viewers' movements in the exploration and also provide feedback, which can be used for revising the display and fluid interactivity, thereby enabling interaction with a real-time environment.

Loeffler and Anderson (1994) mentioned that VR environments share four elements: They are computergenerated, three-dimensional, simulated, and rendered in real time based on users' behavior. Meanwhile, Zeltzer (1992) described three dimensions of VR: presence, interaction, and autonomy. Navigation and autonomy are important characteristics of VR that are useful for understanding the applications of VR (Thorsteinsson, Page, \& Niculescu, 2010).

\subsection{Applications of Virtual Reality}

There are several applications to create VR environments that are available to the public, such as Worlds (Worlds.com Inc, 2013), Second Life (Linden Research, 2013), and There (Makena Technologies Company, 2013). These are not the only existing VR applications, as several other applications that support different subjects and needs are available for VR environments. For example, River City is a simulation application that supports interactivity and has been used by middle-school science students to learn 21 st century skills and scientific inquiry (Galas \& Ketelhut, 2006). Other applications for VR simulation include Vfrog, where learners can dissect a virtual frog (Lee, Wong, \& Fung, 2010), and MAY3D, which assists high-school students in learning different mathematical concepts (Pasqualotti \& Freitas, 2002). Furthermore, DimensionM is a 3D 
video game that provides learners with the experience of embarking on a journey and accomplishing a series of tasks that must be solved through applying different mathematical principles (Kebritchi, Hirumi, \& Bai, 2010). Therefore, VR applications can support the learning process in several unique ways. However, among them, the most popular application for 3D VR is Second Life (SL) developed by Linden Lab. SL is an excellent VR application that allows users to gain practical experience and explore their knowledge. It connects many users and enables them to interact with one another in a VE through role playing, or the use of avatars. Therefore, it supports rich communication, content, and virtual collaboration (Andreas, Tsiatsos, Terzidou, \& Pomportsis, 2010; Hobbs, Brown, \& Gordon, 2006). Accordingly, SL has great potential in the education sector for enhancing both teaching and learning (Jamaludin, San, \& Ho, 2009).

\section{Discussion}

\subsection{Importance of Implementing VR in Education}

The implementation of VR in education can provide enormous benefits such as supporting and enhancing teaching and learning processes. Numerous research studies have examined the effectiveness of different learning methods in a general educational setting, although fewer studies have examined the impact of VR on education (Thorsteinsson et al., 2010). However, some studies have been conducted to explore the effectiveness of VR as an educational technology (Thorsteinsson et al., 2010; Winn, 1993). Some studies were carried out in the short term and others in the long term as part of a plan to develop VR for use in schools. Based on the literature review, I will present and discuss the benefits of VR for educational purposes at following, specifically for teaching and students' learning.

\subsection{Collaborative/Cooperative Learning}

In a collaborative/cooperative environment, students are able to exchange their ideas in groups, share experiences, and cooperate with one another while gaining knowledge during their learning process (Dimitropoulos, Manitsaris, \& Mavridis, 2008). However, Taxén and Naeve (2002) stated that teachers and educators must adapt their teaching methods to the VR environment. VR technology that supports immersive learning has huge benefits for social scaffolding in collaborative and cooperative learning (Hodge, Tabrizi, Farwell, \& Wuensch, 2008; Sherman \& Craig, 2003). For example, collaborative learning could be achieved in the VR environment by involving multiple users who interact in the same simulation or virtual space. Users can perceive the existence of others in the simulation via the use of avatars, which may also be considered as learners' proxies (Sherman \& Craig, 2003). In this regard, avatars along with chat rooms enable learners to share a common learning process and be aware of one another in the shared virtual space. Learners and instructors can communicate using two tools: tech chats or visual lectures. In this regard, a collaborative and cooperative environment has been shown to foster learners' sociability and adaptability (Pan, Cheok, Yang, Zhu, \& Shi, 2006), enabling them to develop their social skills. Also, collaborative learning environments support critical thinking, thereby helping leaners to develop problem-solving skills. Finally, such environments often encourage greater interest among learners (Dimitropoulos et al., 2008). Consequently, a collaborative VR environment may be a powerful tool for fostering learning processes.

\subsection{Creative Learning}

As knowledge is a dynamic process, educators need to progressively encourage self-reflective learning but also lead learners with their own creativity. According to Claxton (1999), creativity can be gained and learned. To achieve this, educators might integrate creativity in their curriculum to offer a subject-oriented basis for the activities of reflective learning. Moreover, Hsiao et al. (2006) considered creativity to be one of the main resources for solving problems. Isaksen and Parnes (1985) argued that creative thinking, creative learning, and problem solving are related to each other. Indeed, most problems require creative thinking to solve them. Thus, learners must be able to apply creativity in their thinking and problem solving. A creative imagination can enable students to visualize new concepts not immediately present in their senses and map them inside their minds (Singer, 1999).

VR can play an important role in supporting and enhancing students' creative learning. Specifically, the imaginative aspect of VR can promote learners to develop their capacity to solve problems, especially openended problems. Moreover, creative visualization is one of the techniques that can assist learners in developing their imagination and can support users in learning topics of the interest in the VR environment. Learners have been shown to apply knowledge gained from imaginative play, such as from games, and to employ both convergent and divergent thinking to build new knowledge (Turvey, 2006). From a constructive framework, instructional designers could apply or combine strategies different into the design of a VR course. For instance, Sims (2007) applied collaborative learning and role playing in a VR learning environment to improve learners' retention and motivation. Thus, VR technology deserves to receive greater attention as an instructional tool to stimulate creativity from both educators and policy makers, as it can clearly support learners' creativity in various ways. 


\subsection{Problem-Based Learning}

The ability to solve problems is considered a critical learning skill. Therefore, educators should adopt a problem-based learning (PBL) approach to improve learners' problem-solving skills. The PBL approach is centered on the learner and supports learners in solving problems by first highlighting the problem. For instance, a case study might be presented to a group of learners followed by a small group discussion with minimum intervention from others aside from a facilitator.

In this regard, VR can play an important role in enhancing and supporting students' problem-solving skills. For example, a potential problem can be simulated in the VR environment, or an authentic problem may be posed and solved through tasks with a vague structure. In this regard, designers have the ability to create distinct levels of difficulty as a means of individualizing the experience. Also, immediate feedback can be provided, which may be more realistic than feedback provided during didactic instruction (Brenton et al., 2007; Holmes, 2007). Furthermore, a VR learning environment enables multiple leaners to observe a similar situation and learn or solve a problem within an interactive and immersive environment. It provides users with a rich learning environment and enables learners to collectively undertake, solve, and visualize problems in a group (Wollensak, 2002) and discuss their thinking with others. Importantly, problem-solving exercises are important for teaching learners how to value different facets of a problem.

Consequently, the implementation of the PBL approach in a VR environment can immerse students in a context that encourages the exploration of different problem constructs. Eventually, learners could be encouraged to freely discover in the VR learning environment and to build their own new knowledge via problem-solving processes. Therefore, the VR learning environment can support a reflexive, dynamic, and cooperative learning process.

\subsection{Role Playing}

The research of Sims (2007) and Rauch (2007) on the effective of immersive VR experiences on users indicated that attention should be placed on the nature and role of interactivity. Previously, learners were found to prefer to play and engage in multi-player gaming due to its capacity to provide context and competitive interaction on tasks, including role play (Shih \& Yang, 2008). In this regard, role playing can be implemented in the VR learning environment to support learning. As VR enables learners to explore a virtual world, learners can act via the $3 \mathrm{D}$ graphic representation of avatars or characters, which allow learners to take on specific personalities or characteristics (Holmes, 2007). On the other hand, when learners feel safe in a VR learning environment, they can express what they feel or think through using an avatar or character that simulates their imagination and creativity (Pan et al., 2006). An appropriate description of this process might be edutainment, or the integration of education with computer games. Interactivity and immersion are considered as two key aspects that add to the value of VR. Therefore, integrating games and role play with the VR learning environment can be an appropriate method for motivating and enhancing students' learning.

\subsection{Limitations of $V R$}

Despite the huge benefits and advantages associated with the implementation of VR in education, including teaching and learning processes, there are also some drawbacks with this technology. Most of VR systems still have some of the following limitations:

- When systems are offline, there is no cooperation from educators.

- Most educational activities such as lectures, seminars, and work teams have not yet incorporated the advantages of VR simulation.

- The level of interaction between learners in VR systems is still low.

- $\quad$ Limited spaces may be available for VR learners.

In addition, one of the main reasons why VR has not yet reached its full potential or achieved greater use in schools is related to its financial feasibility (Mantovani, Castelnuovo, Gaggioli, \& Riva, 2003; Merchant et al., 2012; Riva, 2003). The cost for both the maintenance and procurement of different sophisticated devices for creating an immersive VR environment makes the widespread use of this technology difficult. Moreover, some users have expressed psychological and physical discomforts during the VR experience (Merchant et al., 2012) as a result of repetitive strain injuries, strenuous posture demands, the heavy weight of headsets, or the poor fit of headsets in addition to psychological problems such as dissociation, disorientation, and hallucination (Costello, 1997). Another concern mentioned in several cases in the literature was the poor instructional design of the VR learning environment (Chen, Toh, \& Ismail, 2005; Merchant et al., 2012; Riva, 2003).

However, even though cost was one of the main reasons that prohibited the implementation and use of VR in educational settings, the development of computer software and hardware in recent years has decreased the cost of implementing VR and made it more feasible to incorporate these technologies into future teaching and learning strategies. Despite some of the challenges that remain for the further implementation of VR in education, the educational benefits of the implementation of VR are compelling (Abulrub et al., 2011). Clearly, although VR is associated with numerous benefits that support learning and teaching processes, it is not free of limitations. 


\section{Conclusion}

The present paper reviewed the importance of implementing VR to enhance and support the education sector, namely teaching and students' learning. It began by presenting the definitions of VR from different perspectives as well as different categories and applications of VR. VR technology is constantly evolving and, like other emerging technologies, it presents unique opportunities and challenges in regard to its implementation in the education sector. However, it is necessary to generate a better understanding of these opportunities and challenges. Despite the associated challenges, VR can support teaching and students' learning through encouraging collaborative/cooperative learning, creative thinking, problem-based learning, and role playing. As new VR technologies are continually being developed, the potential uses of VR in the education sector will continue to grow in both importance and number.

\section{References}

Abulrub, A. H. G., Attridge, A. N., \& Williams, M. A. (2011). Virtual reality in engineering education: The future of creative learning. Paper presented at the 2011 IEEE Global Engineering Education Conference (EDUCON).

Andreas, K., Tsiatsos, T., Terzidou, T., \& Pomportsis, A. (2010). Fostering collaborative learning in second life: Metaphors and affordances. Computers \& Education, 55(2), 603-615. Available at: https://doi.org/10.1016/j.compedu.2010.02.021.

Baños, R. M., Botella, C., Alcañiz, M., Liaño, V., Guerrero, B., \& Rey, B. (2004). Immersion and emotion: Their impact on the sense of presence. Cyberpsychology \& Behavior, 7(6), 734-741. Available at: https://doi.org/10.1089/cpb.2004.7.734.

Brenton, H., Hernandez, J., Bello, F., Strutton, P., Purkayastha, S., Firth, T., \& Darzi, A. (2007). Using multimedia and Web3D to enhance anatomy teaching. Computers \& Education, 49(1), 32-53. Available at: https://doi.org/10.1016/j.compedu.2005.06.005.

Chen, C. J., Toh, S. C., \& Ismail, W. M. F. W. (2005). Are learning styles relevant to virtual reality? Journal of Research on Technology in Education, 38(2), 123-141.

Claxton, G. (1999). Wise up. The challenge of lifelong learning. New York, NY 10010: Bloomsbury Publishing, 175 Fifth Avenue.

Conn, C., Lanier, J., Minsky, M., Fisher, S., \& Druin, A. (1989). Virtual environments and interactivity: Windows to the future. ACM Siggraph Computer Graphics, 23(5), 7-18. Available at: https://doi.org/10.1145/77277.77278.

Costello, P. J. (1997). Health and safety issues associated with virtual reality: A review of current literature (pp. 1-23). Loughborough, UK: Advisory Group on Computer Graphics.

Dimitropoulos, K., Manitsaris, A., \& Mavridis, I. (2008). Building virtual reality environments for distance education on the web: A case study in medical education. International Journal of Social Sciences, 2(1), 62-70.

Galas, C., \& Ketelhut, D. J. (2006). River city, the MUVE. Learning and Leading with Technology, 33(7), 31-41.

Gibson, W. (1984). Neuromancer. New York: Ace Books.

Gutierrez, M., Vexo, F., \& Thalmann, D. (2008). Stepping into virtual reality: Springer Science \& Business Media.

Guttentag, D. A. (2010). Virtual reality: Applications and implications for tourism. Tourism Management, 31(5), 637-651. Available at: https://doi.org/10.1016/j.tourman.2009.07.003.

Hobbs, M., Brown, E., \& Gordon, M. (2006). Using a virtual world for transferable skills in gaming education. Innovation in Teaching and Learning in Information and Computer Sciences, 5(3), 1-13. Available at: https://doi.org/10.11120/ital.2006.05030006.

Hodge, E. M., Tabrizi, M., Farwell, M. A., \& Wuensch, K. L. (2008). Virtual reality classrooms: Strategies for creating a social presence. International Journal of Social Sciences, 2(2), 105-109.

Holmes, J. (2007). Designing agents to support learning by explaining. Computers \& Education, 48(4), 523-547.

Hsiao, H. S., Wong, K. H., Wang, M. J., Yu, K. C., Chang, K. E., \& Sung, Y. T. (2006). Using cognitive affective interaction model to construct on-line game for creativity. Paper presented at the International Conference on Technologies for E-Learning and Digital Entertainment. Heidelberg, Springer, Berlin No. 409-418.

Isaksen, S. G., \& Parnes, S. J. (1985). Curriculum planning for creative thinking and problem solving. The Journal of Creative Behavior, 19(1), 1-29. Available at: https://doi.org/10.1002/j.2162-6057.1985.tbo0400.x.

Jamaludin, A., San, C. Y., \& Ho, C. M. L. (2009). Fostering argumentative knowledge construction through enactive role play in second life. Computers \& Education, 53(2), 317-329. Available at: https://doi.org/10.1016/j.compedu.2009.02.009.

Kebritchi, M., Hirumi, A., \& Bai, H. (2010). The effects of modern mathematics computer games on Mathematics achievement and class motivation. Computers \& Education, 55(2), 427-443. Available at: https://doi.org/10.1016/j.compedu.2010.02.007.

Krueger, M. (1970). Videoplace-an artificial reality. ACM SIGCHI Bulletin, 16(4), 35-40.

Lee, E. A.-L., Wong, K. W., \& Fung, C. C. (2010). How does desktop virtual reality enhance learning outcomes? A structural equation modeling approach. Computers \& Education, 55(4), 1424-1442. Available at: https://doi.org/10.1016/j.compedu.2010.06.006.

Linden Research. (2013). Second life. Retrieved from https://secondlife.com/whatis/.

Loeffler, C., \& Anderson, T. (1994). The virtual reality casebook: John Wiley \& Sons, Inc.

Makena Technologies Company. (2013). There. Retrieved from http://www.there.com/.

Mantovani, F., Castelnuovo, G., Gaggioli, A., \& Riva, G. (2003). Virtual reality training for health-care professionals. Cyberpsychology \& Behavior, 6(4), 389-395. Available at: https://doi.org/10.1089/109493103322278772.

McLellan, H. (1996). Virtual realities. Handbook of Research for Educational Communications and Technology, 457-487.

Merchant, Z., Goetz, E. T., Keeney-Kennicutt, W., Kwok, O.-m., Cifuentes, L., \& Davis, T. J. (2012). The learner characteristics, features of desktop 3D virtual reality environments, and college chemistry instruction: A 
structural equation modeling analysis. Computers $\mathcal{E}^{\circ}$ Education, 59(2), 551-568. Available at: https://doi.org/10.1016/j.compedu.2012.02.004.

Pan, Z., Cheok, A. D., Yang, H., Zhu, J., \& Shi, J. (2006). Virtual reality and mixed reality for virtual learning environments. Computers \& Graphics, 30(1), 20-28. Available at: https://doi.org/10.1016/j.cag.2005.10.004.

Pantelidis, V. S. (1993). North Carolina competency-based curriculum objectives and virtual reality. Greenville, NC: Virtual Reality and Education Laboratory, School of Education, East Carolina University.

Pasqualotti, A., \& Freitas, C. M. D. S. (2002). MAT3D: A virtual reality modeling language environment for the teaching and learning of Mathematics. Cyberpsychology $\mathcal{E}^{\circ}$ Behavior, 5(5), 409-422. Available at: https://doi.org/10.1089/109493102761022832.

Rauch, U. (2007). Who owns this space anyway? (pp. 4249-4253). The Arts 3D VL Metaverse as a Network of Imagination. In EdMedia+ Innovate Learning. Association for the Advancement of Computing in Education (AACE).

Riva, G. (2003). Applications of virtual environments in medicine. Methods of Information in Medicine, 42(05), 524-534.

Sanchez-Vives, M. V., \& Slater, M. (2005). From presence to consciousness through virtual reality. Nature Reviews Neuroscience, 6(4), 332-339. Available at: https://doi.org/10.1038/nrn1651.

Schwienhorst, K. (1998). The 'third place'-virtual reality applications for second language learning. ReCALL, 1O(1), 118126.

Sherman, W. R., \& Craig, A. B. (2003). Understanding virtual reality. San Francisco CA: Morgan Kauffman.

Shih, Y.-C., \& Yang, M.-T. (2008). A collaborative virtual environment for situated language learning using VEC3D. Journal of Educational Technology \& Society, 11(1), 56-68.

Sims, E. M. (2007). Reusable, lifelike virtual humans for mentoring and role-playing. Computers \& Education, 49(1), 75-92. Available at: https://doi.org/10.1016/j.compedu.2005.06.006.

Singer, J. L. (1999). Imagination. Encyclopedia of Creativity, 2(1), 13-25.

Stapleton, C., Hughes, C., Moshell, M., Micikevicius, P., \& Altman, M. (2002). Applying mixed reality to entertainment. Computer, 35(12), 122-124.

Taxén, G., \& Naeve, A. (2002). A system for exploring open issues in VR-based education. Computers \& Graphics, 26(4), 593-598. Available at: https://doi.org/10.1016/s0097-8493(02)00112-7.

Thorsteinsson, G., Page, T., \& Niculescu, A. (2010). Using virtual reality for developing design communication. Studies in Informatics and Control, 19(1), 93-106. Available at: https://doi.org/10.24846/v19i1 y201010.

Turvey, K. (2006). Towards deeper learning through creativity within online communities in primary education. Computers E Education, 46(3), 309-32 1. Available at: https://doi.org/10.1016/j.compedu.2005.11.004.

Vince, J. (2004). Introduction to virtual reality. New York: Springer.

Winn, W. (1993). A conceptual basis for educational applications of virtual reality. Technical Publication R-93-9, Human Interface Technology Laboratory of the Washington Technology Center. Seattle: University of Washington.

Wollensak, A. (2002). Curricular modules: 3D and immersive visualization tools for learning. Computers \& Graphics, 26(4), 599-602. Available at: https://doi.org/10.1016/s0097-8493(02)00110-3.

Worlds.com Inc. (2013). Worlds. Retrieved from http://www.worlds.com/.

Zeltzer, D. (1992). Autonomy, interaction, and presence. Presence: Teleoperators छ Virtual Environments, 1(1), 127-132. Available at: https://doi.org/10.1162/pres.1992.1.1.127.

Zyda, M. (2005). From visual simulation to virtual reality to games. Computer, 38(9), 25-32. Available at: https://doi.org/10.1109/mc.2005.297. 